Check for updates

Cite this: RSC Adv., 2018, 8, 36761

\title{
High-performance multi-functional graphene/ hexagonal boron nitride/poly(ethylene oxide) nanocomposites through enhanced interfacial interaction by coordination
}

\begin{abstract}
Chen Lin, $\mathbb{D}^{a}$ Xiong-Ying $\mathrm{Ye}^{\star \mathrm{b}}$ and Xu-Ming Xie ${ }^{\star a}$
In this study, multi-functional nanocomposites with excellent mechanical, electrical and thermal properties were prepared through metal-ion coordination. Reduced graphene oxide ( $\mathrm{rGO}$ ) and hexagonal boron nitride ( $\mathrm{h}-\mathrm{BN}$ ) interacted through calcium coordination bonding. Poly(ethylene oxide) (PEO) was added to bridge these two nanomaterials, providing more resistance to tensile deformation. The results of UVVis and FTIR spectra proved that coordination bonding was successfully formed among the three compounds. SEM images showed homogenous dispersions of the nanocomposite. After calcium-ion coordination, the mechanical, electrical and thermal properties of $\mathrm{Ca}^{2+}$-coordinated $\mathrm{rGO} / \mathrm{BN} / \mathrm{PEO}$ composite improved significantly, indicating that metal-ion coordination is a potential method for multifunctional nanocomposite fabrication.
\end{abstract}

Received 26th July 2018

Accepted 5th October 2018

DOI: $10.1039 / \mathrm{c} 8 \mathrm{ra06325g}$

rsc.li/rsc-advances

threshold and high electrical conductivity, which was due to

\section{Introduction}

Two-dimensional materials, such as graphene and hexagonal boron nitride (h-BN), have attracted significant attention in recent years because of their unique structures and excellent properties. Graphene is a one-atom-thick nanomaterial composed of $\mathrm{sp}^{2}$-hybridized carbons. It is the most well-known representative of two-dimensional material and has outstanding mechanical (Young's modulus, $\sim 1$ TPa; ultimate strength, $\sim 130 \mathrm{GPa}$ ) and electrical (conductivity, $\sim 6000 \mathrm{~S} \mathrm{~cm}^{-1}$ ) properties. ${ }^{1,2}$ Reduced graphene oxide (rGO) is one of the derivatives of graphene; it can be easily synthesized and shows similar mechanical and electrical performances to those of graphene. Thus, rGO is usually used as a substitute for pristine graphene. ${ }^{3,4}$ Hexagonal boron nitride is also a novel two-dimensional material, which is composed of covalently connected nitrogen and boron atoms arranged in an alternating manner; ${ }^{5,6}$ it has remarkable properties such as high thermal stability, high thermal conductivity, high oxidation resistance and a low dielectric constant. Because of their outstanding properties, rGO and BN are excellent candidates to synthesize high-performance nanocomposites.

However, in most previous reports, researchers always focused on only one of these nanomaterials. ${ }^{7-11}$ Zheng et al. ${ }^{7}$ prepared an rGO/PA6 nanocomposite with low percolation

\footnotetext{
${ }^{a}$ Laboratory of Advanced Materials (MOE), Department of Chemical Engineering, Tsinghua University, Beijing 100084, China. E-mail: xxm-dce@mail.tsinghua.edu.cn ${ }^{b}$ Department of Precision Instrument, Tsinghua University, Beijing 100084, China. E-mail: xyye@mail.tsinghua.edu.cn
} excellent electrical properties of rGO. Song et al. ${ }^{10}$ prepared $\mathrm{BN} /$ PVA nanocomposites with high thermal diffusivity due to excellent thermal conductivity of BN. Although some studies on graphene/BN composites have been performed, ${ }^{12-15}$ the two nanomaterials do not exhibit their respective properties simultaneously. For example, BN/GO and BN/graphene papers with high thermal conductivities were prepared by Yao et al. ${ }^{\mathbf{1 3}}$ and Liem et al. ${ }^{14}$ respectively; however, they only utilized the high thermal property of h-BN. The excellent properties of graphene, such as mechanical property and electrical property, were not utilized. To the best of our knowledge, research on composites with multiple $2 \mathrm{D}$ nanomaterials is insufficient because there is no universal method to bond 2D materials and take advantage of their combined properties.

In this article, coordination bonding, as a dynamic covalent bonding, was chosen to enhance the interfacial interaction between rGO and BN. In our previous studies, ${ }^{16-21}$ coordination bonding was used to provide strong interactions in many systems. After being reduced, rGO still has residual oxidized functional groups such as carboxyl groups and hydroxyl groups. These groups can be coordinated with B-N bonds through metal-ion coordination. Furthermore, to increase the elongation at break of the nanocomposite, we chose poly(ethylene oxide) (PEO), which could also be coordinated through metal ions, to bridge rigid 2D nanomaterials. With enhanced interaction provided by metal-ion coordination, the rGO/BN/PEO composite showed excellent performances in all mechanical, electrical and thermal aspects. 
Herein, we report a novel strategy for bridging different 2D nanomaterials by metal-ion coordination to utilize the excellent properties of each in one system. This simple and cost-effective method is applicable to a variety of nanomaterials (and polymers, if needed) containing coordination atoms. Thus, a new opportunity to prepare high-performance multi-functional nanocomposites can be achieved by this strategy.

\section{Experimental}

\section{Raw materials}

Graphite (325 mesh) powder was purchased from Qingdao Xinghe Graphite Co. Ltd. h-BN (diameter $=\sim 1 \mu \mathrm{m}$, purity > 98\%) powder and calcium chloride were both purchased from Sigma Aldrich Corporation. PEO $\left(M_{\mathrm{w}}=\sim 100000\right)$ was purchased from Alfa-Aesar Corporation. Also, 98\% sulfuric acid, $37 \%$ hydrochloric acid, 30\% hydrogen peroxide, potassium permanganate, sodium nitrate, and hydrazine hydrate were all purchased from Beijing Chemical Works. All chemicals were used as received.

\section{Fabrication of $\mathrm{Ca}^{2+}$-coordinated rGO/BN/PEO nanocomposite}

In our experiments, the ratio of $\mathrm{Ca}^{2+} /(\mathrm{rGO}+\mathrm{BN})$ in the coordinated composites was kept constant at $0.001 \mathrm{~mol} \mathrm{~g}^{-1}$.

Graphene oxide was prepared from natural powder according to our previous reports by a modified Hummers method..$^{18,19,21-23}$ The fabrication procedure of $\mathrm{Ca}^{2+}$-coordinated $\mathrm{rGO} / \mathrm{BN} / \mathrm{PEO}$ nanocomposite films was as follows: GO aqueous solution was diluted to $2 \mathrm{mg} \mathrm{mL}^{-1}$ after preparation. BN was dispersed into deionized water using an ultrasonic bath (Kunshan Ultrasonic Instrument Co., Ltd, model: KQ100DE, $100 \mathrm{~W}$ ) for $8 \mathrm{~h}$. The obtained slurry was then centrifuged at $9000 \mathrm{rpm}$ for $40 \mathrm{~min}$. The top $2 / 3$ supernatant was collected. The concentration of this $\mathrm{BN}$ aqueous solution was determined by drying a fixed volume and weighing the remaining solid. The result was $1.2 \mathrm{mg} \mathrm{mL}^{-1}$. PEO was dissolved in deionized water and stirred under room temperature to obtain $8 \mathrm{mg} \mathrm{mL}^{-1}$ PEO aqueous solution. The three solutions were mixed and then, $2 \mathrm{mg} \mathrm{mL}{ }^{-1} \mathrm{CaCl}_{2}$ aqueous solution was added. The mixed solution was kept at $50{ }^{\circ} \mathrm{C}$ for $0.5 \mathrm{~h}$ for coordination. Hydrazine hydrate at $0.8 \mathrm{~L} \mathrm{~g}^{-1}$ of GO was then added, and the solution was kept at $80{ }^{\circ} \mathrm{C}$ for $8 \mathrm{~h}$ for reduction. After that, the solution was poured into Teflon Petri dishes for deposition at $50{ }^{\circ} \mathrm{C}$ for $24 \mathrm{~h}$. Finally, they were kept in a vacuum oven at $50{ }^{\circ} \mathrm{C}$ to remove residual water.

\section{Characterization}

GO and BN aqueous solutions were prepared for AFM observation. Samples were kept at $50{ }^{\circ} \mathrm{C}$ for $0.5 \mathrm{~h}$ for coordination and then spin-coated on mica at $2000 \mathrm{rpm}$ for $1 \mathrm{~min}$. The AFM observation was obtained using Shimadzu SPM-9700 in the tapping mode. To calculate the number-average thickness of GO and $\mathrm{BN}, 50$ sheets of each nanomaterial were measured. For UVVis characterization, $\mathrm{rGO} / \mathrm{BN} / \mathrm{PEO}$ and $\mathrm{Ca}^{2+}$-coordinated $\mathrm{rGO} /$ $\mathrm{BN} / \mathrm{PEO}$ aqueous solutions were prepared. Samples were kept at $50{ }^{\circ} \mathrm{C}$ for $0.5 \mathrm{~h}$ for coordination. UV-Vis analysis was performed by a PERSEE TU-1810 spectrophotometer. The wavelength range was 200-900 $\mathrm{nm}$. For FTIR characterization, $\mathrm{rGO} / \mathrm{BN} / \mathrm{PEO}$ and $\mathrm{Ca}^{2+}$-coordinated $\mathrm{rGO} / \mathrm{BN} / \mathrm{PEO}$ nanocomposites were scanned by an AVATAR 360 FTIR spectrometer. For Raman spectrum analysis, a RENISHAW RM2000 spectrometer was used with $514 \mathrm{~nm}$ laser excitation. The samples were $\mathrm{Ca}^{2+}$-coordinated $\mathrm{GO} / \mathrm{BN} / \mathrm{PEO}$ and $\mathrm{Ca}^{2+}$-coordinated $\mathrm{rGO} /$ $\mathrm{BN} / \mathrm{PEO}$ filtered films. To calculate the intensity ratio of $I_{\mathrm{D}} / I_{\mathrm{G}}$, 5 different areas of each sample were measured for averaging. The morphologies and structures of the nanocomposites were characterized by scanning electron microscopy (SEM) with a TESCAN VEGA 3 SBH-EasyProbe. For tensile strength tests, the films were cut into $10 \mathrm{~mm} \times 3 \mathrm{~mm} \times 50 \mu \mathrm{m}$ strips. The tensile tests were performed under a speed of $100 \mu \mathrm{m} \mathrm{s}^{-1}$. For electrical conductivity tests, the composites were cut into $10 \mathrm{~mm} \times 3 \mathrm{~mm}$ $\times 50 \mu \mathrm{m}$ strips and characterized by a KEITHLEY 327 voltage current tester. For thermal conductivity tests, samples were cut into $10 \mathrm{~mm} \times 3 \mathrm{~mm} \times 20 \mu \mathrm{m}$ strips and then characterized by a LFA427 laser thermal conductance instrument. In the mechanical, electrical and thermal tests, five different samples were tested for average values.

\section{Results and discussion}

Fig. 1a and b show two typical atomic force microscopy (AFM) images of $\mathrm{GO}$ and $\mathrm{BN}$ sheets that are spin-coated on mica at $2000 \mathrm{rpm}$ for $1 \mathrm{~min}$. The thickness of the GO sheet is $1.03 \mathrm{~nm}$, corresponding to the thickness of a GO monolayer (0.8-1.2 $\mathrm{nm}) .{ }^{24}$ The thickness of the BN sheet is $0.94 \mathrm{~nm}$, corresponding to the thickness of 2-3 layers of $\mathrm{BN}$ monolayer (0.33-0.34 $\mathrm{nm}) .{ }^{10,25}$ The diameter of GO is about $1 \mu \mathrm{m}$, which is much larger than that of $\mathrm{BN}$ (about $0.5 \mu \mathrm{m}$ ). Both nanomaterials have large aspect ratios. Fig. 1c and d show thickness distributions of GO and BN counted from AFM images. The average thickness of GO is $1.75 \mathrm{~nm}$ and that of $\mathrm{BN}$ is $1.12 \mathrm{~nm}$. This result shows that majority of these two nanomaterials are few-layers, indicating that both GO and BN have been fully exfoliated.

The mass ratio of $\mathrm{PEO} /(\mathrm{rGO}+\mathrm{BN})$ is important for the properties of the composite; if it is too low, the film will be fragile and unusable and if it is too high, the electrical and thermal properties of the composite will decrease. Taking these into consideration, in this study, the ratio of $\mathrm{PEO} /(\mathrm{rGO}+\mathrm{BN})$ is always kept at $4: 10$. The UV-Vis spectra of an rGO/BN/PEO aqueous solution before and after coordination are shown in Fig. 2. Since the UV-Vis spectra of PEO and BN are nearly featureless within the $200-900 \mathrm{~nm}$ range, ${ }^{5,16}$ the characteristic peaks are derived from rGO. The major peak at $242 \mathrm{~nm}$ is due to the $\pi \rightarrow \pi^{*}$ transition of $\mathrm{C}-\mathrm{C}$ bonds; the shoulder peak at $305 \mathrm{~nm}$ is due to the $\mathrm{n} \rightarrow \pi^{*}$ transition of the residual $\mathrm{C}=\mathrm{O}$ bonds. ${ }^{26}$ As seen from Fig. 2b, the shoulder peak at $305 \mathrm{~nm}$ becomes much weaker after calcium-ion coordination, which is probably related to the complexation between $\mathrm{C}=\mathrm{O}$ bonds of rGO sheets and $\mathrm{Ca}^{2+}$ ions.

FTIR analysis was performed to further prove the successful coordination on rGO, BN and PEO, as shown in Fig. 3. The characteristic peaks at $\sim 1730, \sim 1680, \sim 1375$ and $\sim 1270 \mathrm{~cm}^{-1}$ correspond to the residual $\mathrm{C}=\mathrm{O}$ bonds on the edge of $\mathrm{rGO}$, 


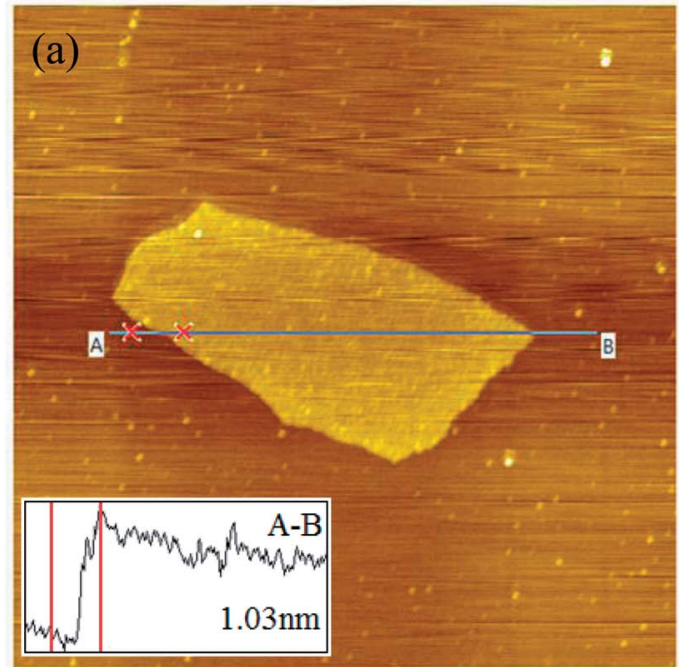

$3 \times 3 \mu \mathrm{m}$

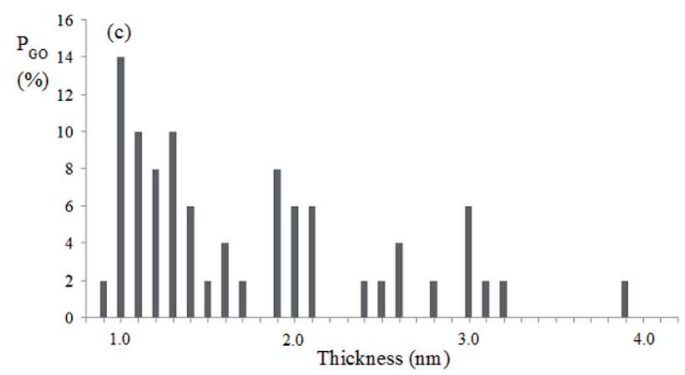

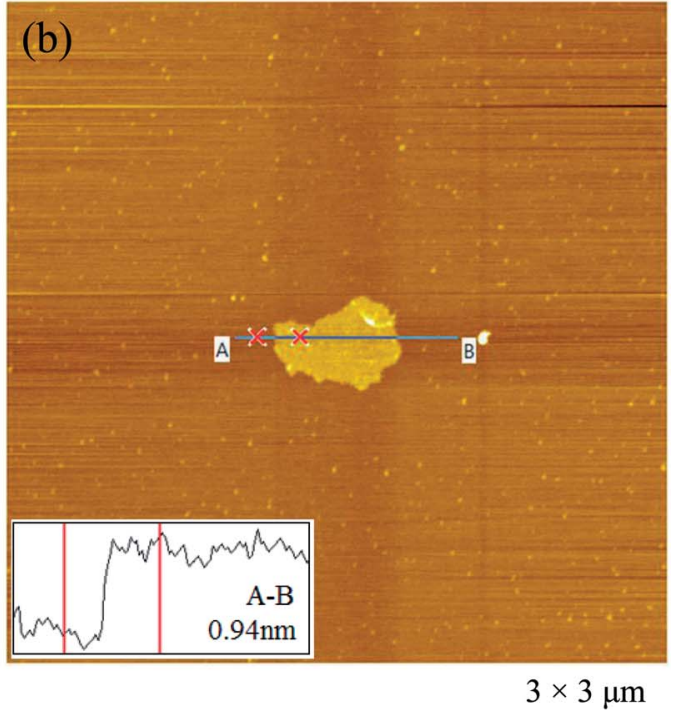

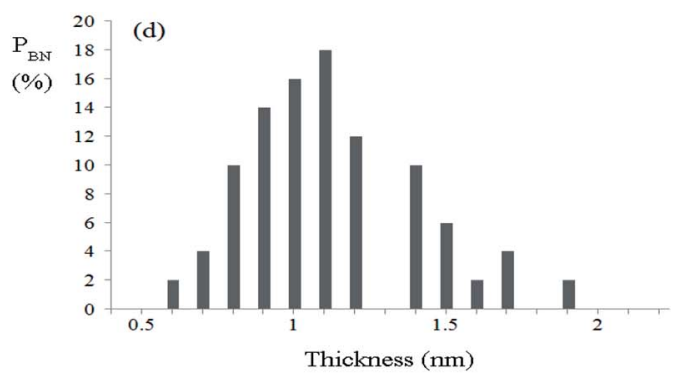

Fig. 1 AFM images of (a) GO and (b) BN aqueous solutions spin-coated on mica at $2000 \mathrm{rpm}$ for 1 min, and thickness distributions of (c) GO and (d) BN sheets counted from their AFM images. The average thickness of GO is $1.75 \mathrm{~nm}$ and that of BN is $1.12 \mathrm{~nm}$.

aromatic $\mathrm{C}=\mathrm{C}$ bonds in the plane of $\mathrm{rGO}, \mathrm{B}-\mathrm{N}$ bonds on $\mathrm{BN}$ sheet and $\mathrm{C}-\mathrm{O}-\mathrm{C}$ bonds on the PEO chain. ${ }^{16,25,27}$ During the coordination process, $\mathrm{Ca}^{2+}$ ions have no effect on $\mathrm{C}=\mathrm{C}$ bonds; thus, the peak at $\sim 1680 \mathrm{~cm}^{-1}$ is chosen as the standard peak. After $\mathrm{Ca}^{2+}$ ions are added, coordination bonds are formed on

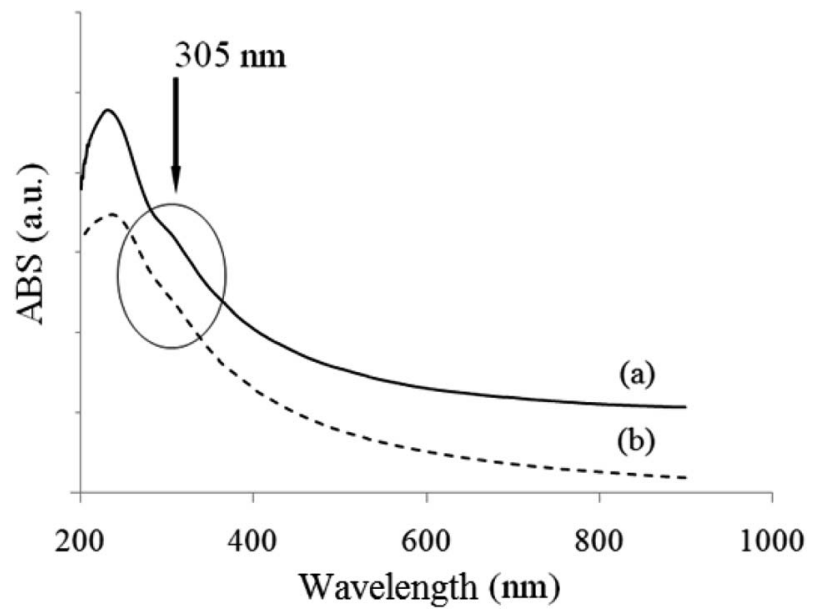

Fig. 2 UV-Vis spectra of (a) rGO/BN/PEO aqueous solution and (b) $\mathrm{Ca}^{2+}$-coordinated $\mathrm{rGO} / \mathrm{BN} / \mathrm{PEO}$ aqueous solution. The mass ratio of $\mathrm{rGO}: \mathrm{BN}:$ PEO is $4: 6: 4$. Both samples were first kept at $50{ }^{\circ} \mathrm{C}$ for $0.5 \mathrm{~h}$ for coordination and then at $80^{\circ} \mathrm{C}$ for $8 \mathrm{~h}$ for reduction. the $\mathrm{C}=\mathrm{O}$ bonds of $\mathrm{rGO}, \mathrm{C}-\mathrm{O}-\mathrm{C}$ bonds of $\mathrm{PEO}$ and $\mathrm{B}-\mathrm{N}$ bonds of $\mathrm{BN}$. After comparing curve $3 \mathrm{~d}$ and curve $3 \mathrm{e}$, it can be seen that the $\mathrm{C}=\mathrm{O}$ peak at $1733 \mathrm{~cm}^{-1}$ decreases significantly, the $\mathrm{C}-\mathrm{O}-\mathrm{C}$

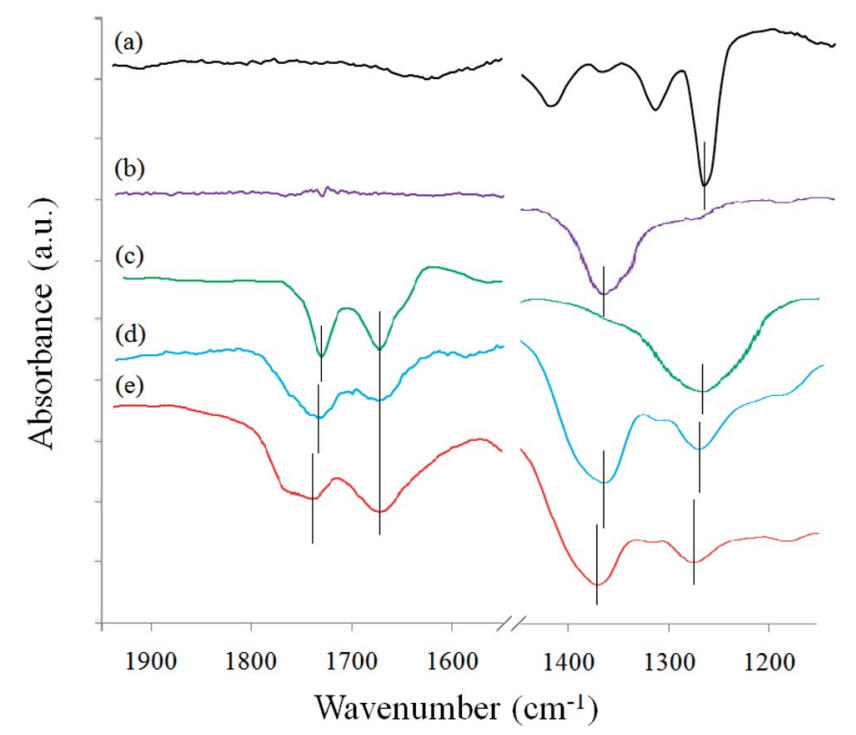

Fig. 3 FTIR spectra of (a) pure PEO, (b) BN, (c) rGO, (d) rGO/BN/PEO and (e) $\mathrm{Ca}^{2+}$-coordinated $\mathrm{rGO} / \mathrm{BN} / \mathrm{PEO}$ nanocomposites. The mass ratio of $\mathrm{rGO}: \mathrm{BN}: \mathrm{PEO}$ is $4: 6: 4$. 


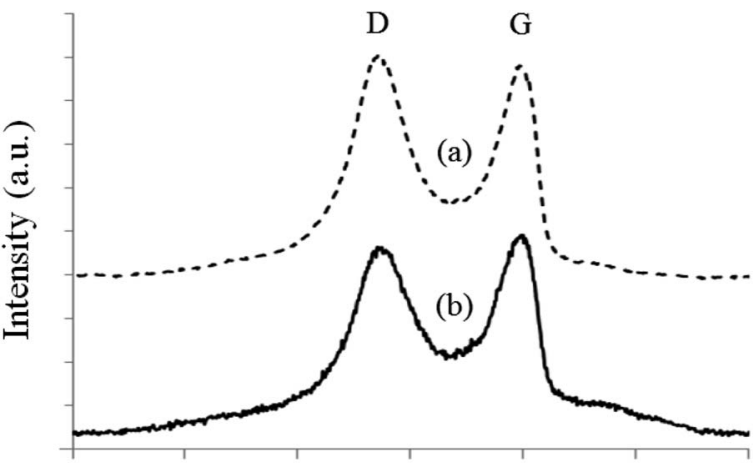

$\begin{array}{lllllll}800 & 1000 & 1200 & 1400 & 1600 & 1800 & 2000\end{array}$

\section{Raman Shift $\left(\mathrm{cm}^{-1}\right)$}

Fig. 4 Raman spectra of (a) $\mathrm{Ca}^{2+}$-coordinated GO/BN/PEO and (b) $\mathrm{Ca}^{2+}$-coordinated $\mathrm{rGO} / \mathrm{BN} / \mathrm{PEO}$ nanocomposites. The mass ratio of both $\mathrm{GO}: \mathrm{BN}$ : PEO and $\mathrm{rGO}: \mathrm{BN}: \mathrm{PEO}$ is $4: 6: 4$.

peak shifts from $1375 \mathrm{~cm}^{-1}$ to $1386 \mathrm{~cm}^{-1}$, and the B-N peak shifts from $1270 \mathrm{~cm}^{-1}$ to $1282 \mathrm{~cm}^{-1}$ after coordination. These results indicate the presence of interactions due to metal-ion coordination. The peak decrease and shift phenomena are similar to the results demonstrated in previous reports. ${ }^{19,28,29}$ The FTIR result is in accordance with the UV-Vis observation, confirming successful coordination in $\mathrm{Ca}^{2+}$-coordinated $\mathrm{rGO} /$ BN/PEO nanocomposite.

Fig. 4 shows the Raman spectra of a $\mathrm{Ca}^{2+}$-coordinated $\mathrm{GO} /$ BN/PEO nanocomposite before and after reduction by hydrazine hydrate. The two major peaks at $\sim 1580 \mathrm{~cm}^{-1}$ and $\sim 1350 \mathrm{~cm}^{-1}$ correspond to the $\mathrm{G}$ peak and the D peak of GO (or $\mathrm{rGO}$ ). The $\mathrm{G}$ peak shows the vibration of the $\mathrm{sp}^{2}$-hybridized carbon in $\mathrm{GO}$ (or rGO), whereas the $\mathrm{D}$ peak shows the structural defects in the graphitic plane. ${ }^{30} \mathrm{The} \mathrm{D} / \mathrm{G}$ intensity ratio $\left(I_{\mathrm{D}} / I_{\mathrm{G}}\right)$ is

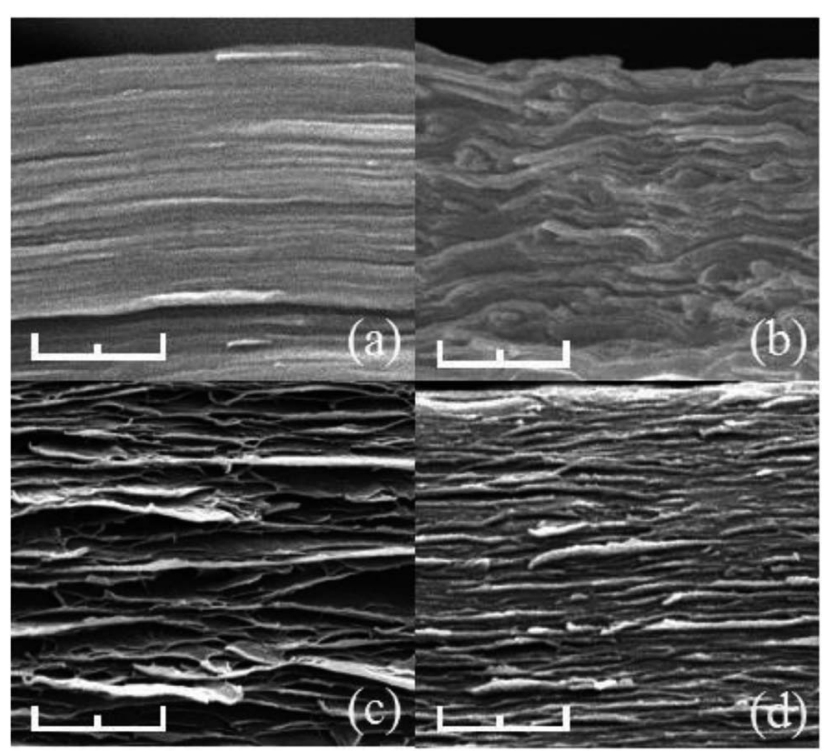

Fig. 5 SEM photographs of (a) rGO, (b) BN, (c) rGO/BN/PEO, (d) $\mathrm{Ca}^{2+}$ coordinated $\mathrm{rGO} / \mathrm{BN} / \mathrm{PEO}$ samples. The mass ratio of $\mathrm{rGO}: \mathrm{BN}: \mathrm{PEO}$ is $4: 6: 4$. The scale bar is $500 \mathrm{~nm}$.

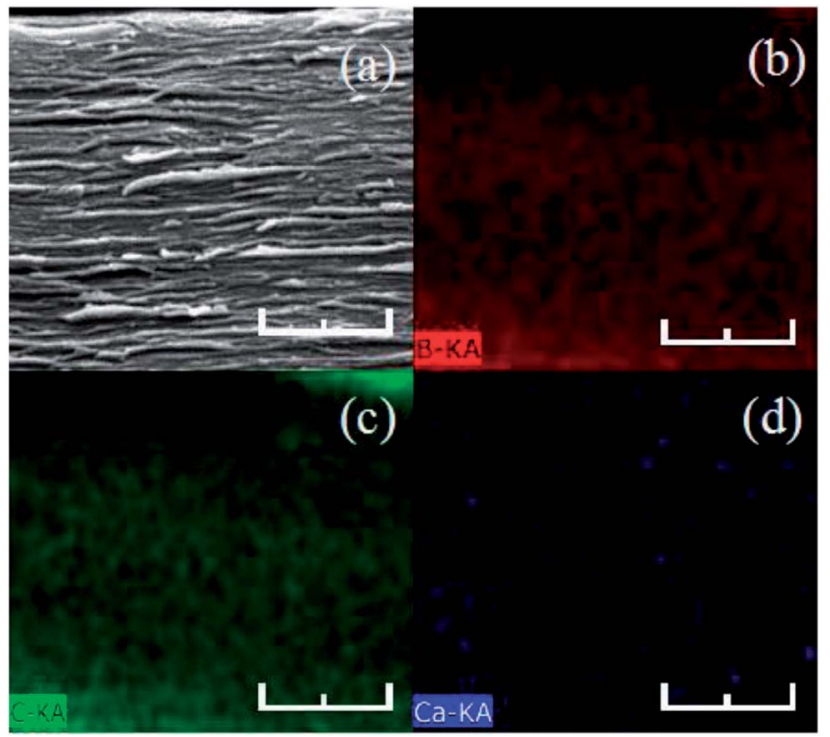

Fig. 6 (a) SEM image and (b) boron, (c) carbon and (d) calcium element energy spectra of $\mathrm{Ca}^{2+}$-coordinated $\mathrm{rGO} / \mathrm{BN} / \mathrm{PEO}$. The mass ratio of $r G O: B N$ : PEO is $4: 6: 4$. The scale bar is $500 \mathrm{~nm}$.

a qualitative measurement of the defects of GO (or rGO). Samples with higher $I_{\mathrm{D}} / I_{\mathrm{G}}$ are considered to have more defects. In Fig. 4 , the $I_{\mathrm{D}} / I_{\mathrm{G}}$ value changes from 1.06 (before reduction, curve 4a) to 0.91 (after reduction, curve 4b), indicating successful reduction of GO. This result is in accordance with previous results. ${ }^{30,31}$

The morphology and structure of the cross-sections of different samples were observed by SEM. As shown in Fig. 5a and b, both $\mathrm{rGO}$ and $\mathrm{BN}$ revealed well-packed layers through almost the whole cross-section of the samples. In rGO/BN/PEO (Fig. 5c) and $\mathrm{Ca}^{2+}$-coordinated rGO/BN/PEO (Fig. 5d), rGO (large sheet, $800-1100 \mathrm{~nm}$ ) and BN (small sheet, 300-600 nm) stacked with each other were bridged by wire-like PEO polymer chains. These results showed a good dispersion state in the composites before and after coordination, indicating that this metal-ion coordination method causes no precipitation of nanomaterials.

Elemental energy spectra of $\mathrm{Ca}^{2+}$-coordinated $\mathrm{rGO} / \mathrm{BN} / \mathrm{PEO}$ composite are shown in Fig. 6. Boron (red dots in Fig. 6b) in the h-BN sheet, carbon (green dots in Fig. 6c) in rGO sheets and PEO chain, and calcium (blue dots in Fig. 6d) were uniformly dispersed and filled almost the entire cross-section. This further improves homogeneous dispersion in the sample, showing that metal-ion coordination does not affect homogeneous dispersion of rGO and BN.

Fig. 7 shows the stress-strain curves of $\mathrm{rGO} / \mathrm{BN} / \mathrm{PEO}, \mathrm{Ca}^{2+}$ coordinated $\mathrm{rGO} / \mathrm{BN}$ and $\mathrm{Ca}^{2+}$-coordinated $\mathrm{rGO} / \mathrm{BN} / \mathrm{PEO}$ nanocomposites. Compared with other samples, the $\mathrm{Ca}^{2+}$-coordinated $\mathrm{rGO} / \mathrm{BN} / \mathrm{PEO}$ sample (curve $7 \mathrm{c}$ ) shows the best mechanical properties (Young's modulus is $1.34 \mathrm{GPa}$, tensile strength is $52 \mathrm{MPa}$ and the elongation at break is $7.9 \%$ ). The sample that has no PEO (curve $7 \mathrm{~b}$ ) exhibits a good Young's modulus (1.15 GPa) but low tensile strength $(22 \mathrm{MPa})$ and elongation $(3.5 \%)$ because it has no elastic polymer chain to bridge rigid $\mathrm{rGO}$ and $\mathrm{BN}$ nanosheets; thus, the composite is 


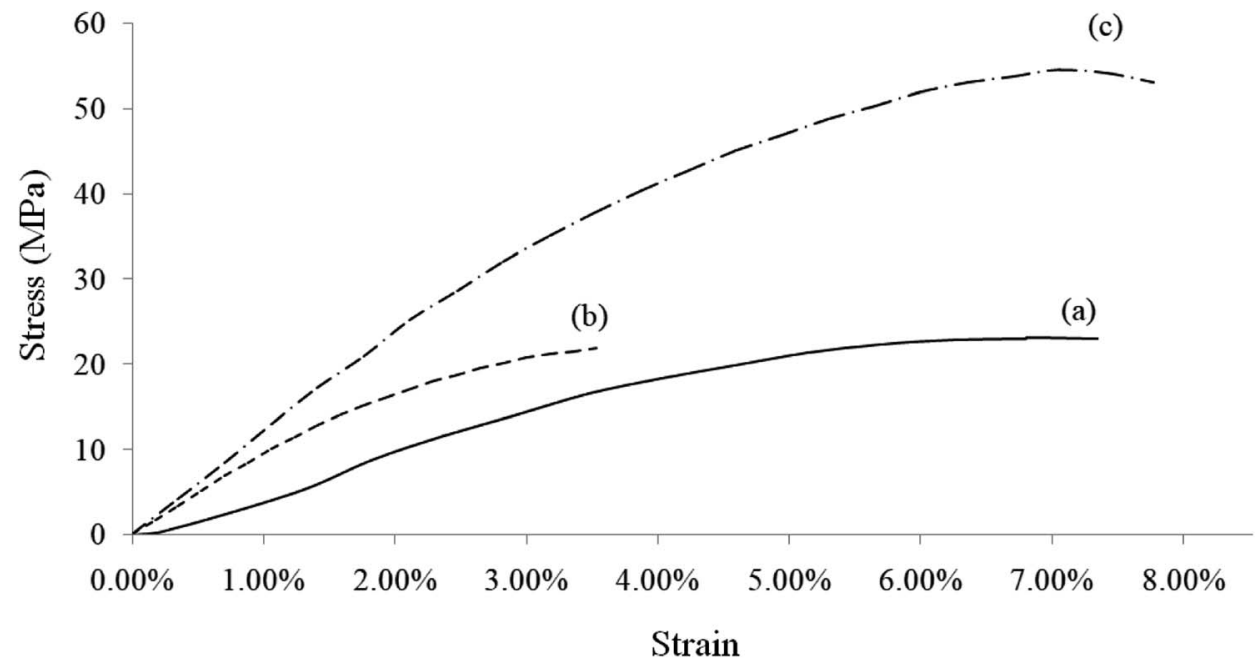

Fig. 7 Stress-strain curves of (a) rGO/BN/PEO, (b) $\mathrm{Ca}^{2+}$-coordinated $\mathrm{rGO} / \mathrm{BN}$ and $(\mathrm{c}) \mathrm{Ca}^{2+}$-coordinated rGO/BN/PEO. The mass ratio of rGO : BN : PEO is constantly $4: 6: 4$.

hard and brittle. The sample without calcium ions (curve 7a) shows good elongation (7.3\%) but low Young's modulus (460 $\mathrm{MPa}$ ) and tensile strength (23 MPa) because there is no coordination bonding to provide strong interfacial interactions between the nanomaterials and the polymer chain. This fact indicates the important roles of both coordination bonds and elastic polymer chains in these composites. From curve $7 \mathrm{a}$ and $7 \mathrm{c}$, it can be seen that after coordination, the mechanical properties of the composite are significantly improved (Young's modulus increases by $191.3 \%$ and tensile strength increases by $126.1 \%)$. Because coordination bonding can realize dynamic interfacial interactions, efficient transfer from the matrix to the dispersed fillers can be achieved. ${ }^{16,32}$
The stress-strain curves of composites with different ratios of $\mathrm{rGO} / \mathrm{BN}$ are shown in Fig. 8. The Young's modulus and tensile strength increase with the increase in the ratio of $\mathrm{rGO} / \mathrm{BN}$ (Young's modulus from $31 \mathrm{MPa}$ to $1.8 \mathrm{GPa}$; tensile strength from $2 \mathrm{MPa}$ to $89 \mathrm{MPa}$ ). This result indicates that samples with a higher ratio of rGO have better mechanical performances because the residual oxidized functional groups on rGO (such as carboxyl group and hydroxyl group) can form coordination bonds with metal ions more easily than B-N groups. Thus, to achieve good mechanical performance, the ratio of $\mathrm{rGO} / \mathrm{BN}$ should not be low.

The electrical conductivity of different composites is shown in Fig. 9. The curves $9 \mathrm{a}$ and $9 \mathrm{~b}$ correspond to the samples before

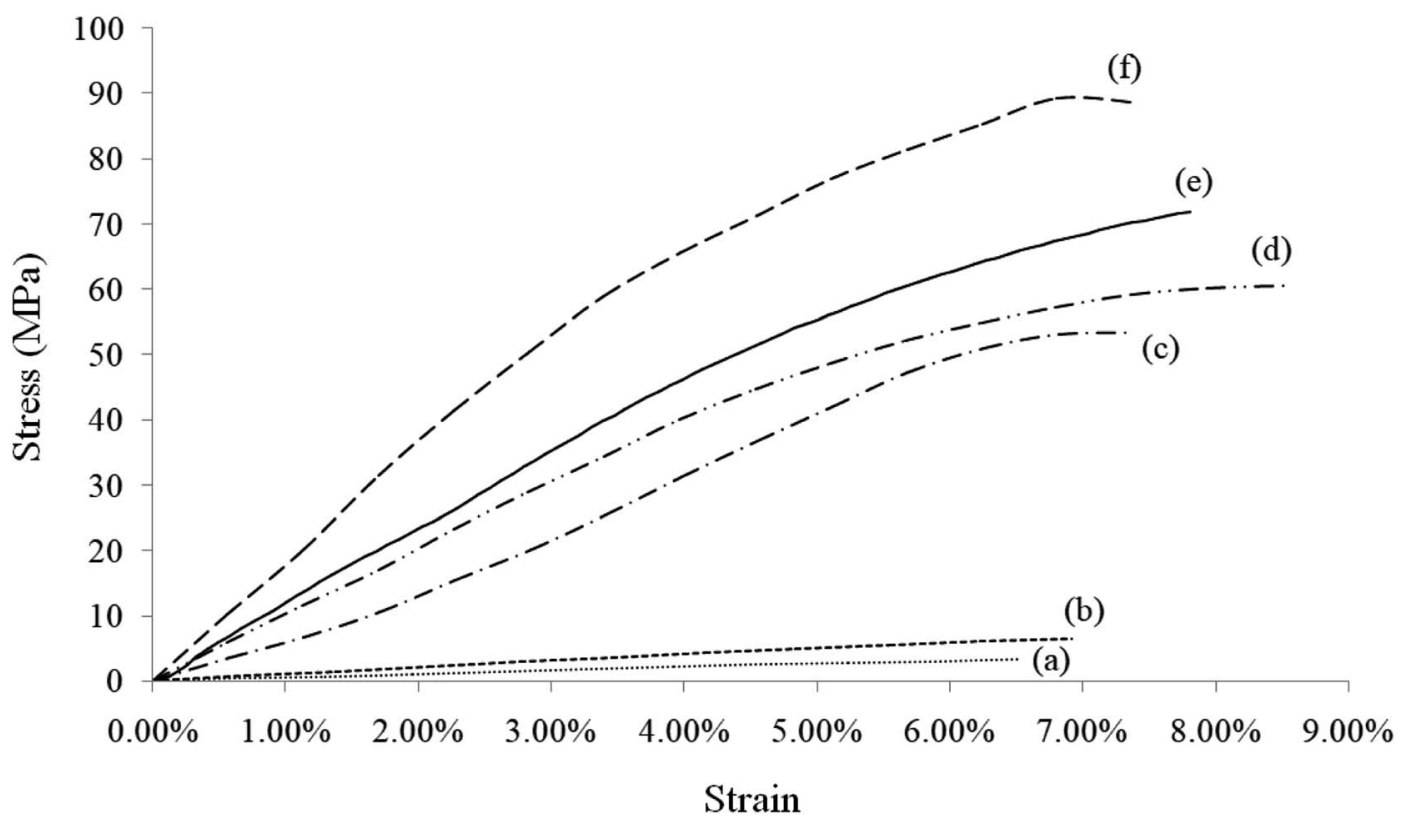

Fig. 8 Stress-strain curves of $\mathrm{Ca}^{2+}$-coordinated $\mathrm{rGO/BN/PEO} \mathrm{nanocomposites.} \mathrm{The} \mathrm{mass} \mathrm{ratios} \mathrm{of} r G O / B N$ are (a) $0: 10$, (b) $2: 8$, (c) $4: 6$, (d) $6: 4$, (e) $8: 2$, (f) $10: 0$. The ratio of $(\mathrm{rGO}+\mathrm{BN}):$ PEO is constantly $10: 4$. 


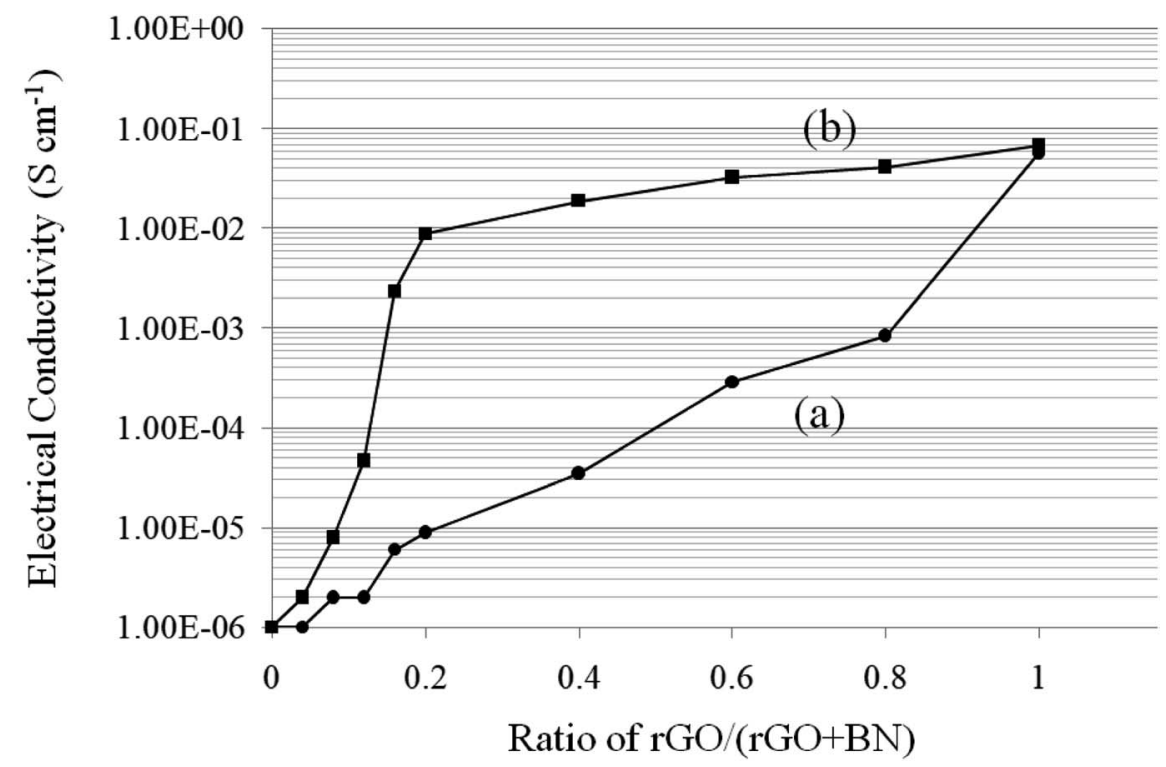

Fig. 9 Electrical conductivity of (a) $\mathrm{rGO} / \mathrm{BN} / \mathrm{PEO}$ and (b) $\mathrm{Ca}^{2+}$-coordinated $\mathrm{rGO} / \mathrm{BN} / \mathrm{PEO}$ nanocomposites. The ratio of $\mathrm{rGO} /(\mathrm{rGO}+\mathrm{BN}$ ) changes from 0 to 1 . The ratio of $(r G O+B N)$ : PEO is constantly $10: 4$.

and after coordination, with the mass ratio of $\mathrm{rGO} /(\mathrm{rGO}+\mathrm{BN})$ changing from 0 (only $\mathrm{BN}$ ) to 1 (only rGO). In all samples, the ratio of PEO is constant. As shown in the two curves, with the increase in rGO content, the electrical conductivity clearly increases (from $\sim 10^{-6} \mathrm{~S} \mathrm{~cm}^{-1}$ to $\sim 10^{-1} \mathrm{~S} \mathrm{~cm}^{-1}$ ) since $\mathrm{rGO}$ is a conductor, whereas $\mathrm{BN}$ is an insulator. When the ratio of rGO is too low, the conductive network cannot form; thus, the sample shows poor electrical conductivity. However, after metal ions are added, the conductivity is improved significantly. The percolation threshold decreases from 0.4 to 0.08 because coordination bonding can dramatically increase the interfacial interaction in the composite. With improvement in interaction, the rGO sheets can form a conductive network more easily (rGO is more likely to be coordinated). As shown in curve $9 \mathrm{~b}$, the electrical conductivity can reach a high value (more than $0.01 \mathrm{~S} \mathrm{~cm}^{-1}$ ) when the ratio of rGO $: \mathrm{BN}$ is $2: 8$.

The thermal conductivity of different composites is shown in Fig. 10. Curve 10a and 10b correspond to the samples before and after coordination. The mass ratio of $\mathrm{rGO} /(\mathrm{rGO}+\mathrm{BN})$ changes from 0 (only $\mathrm{BN}$ ) to 1 (only rGO), as described in previous discussions. In all samples, the ratio of PEO is constant. Because rGO has residual oxidized functional groups on its plane, its $\mathrm{sp}^{2}$ structure contains defects. Thus, h-BN has higher thermal conductivity than rGO. The composites with a higher ratio of BN have better thermal conductive performance. Before coordination, the thermal conductivity of the sample without $\mathrm{BN}$ is $1.5 \mathrm{~W} \mathrm{~m}^{-1} \mathrm{~K}^{-1}$ and that of the sample without $\mathrm{rGO}$ is $3.4 \mathrm{~W} \mathrm{~m}^{-1} \mathrm{~K}^{-1}$. After coordination, the thermal

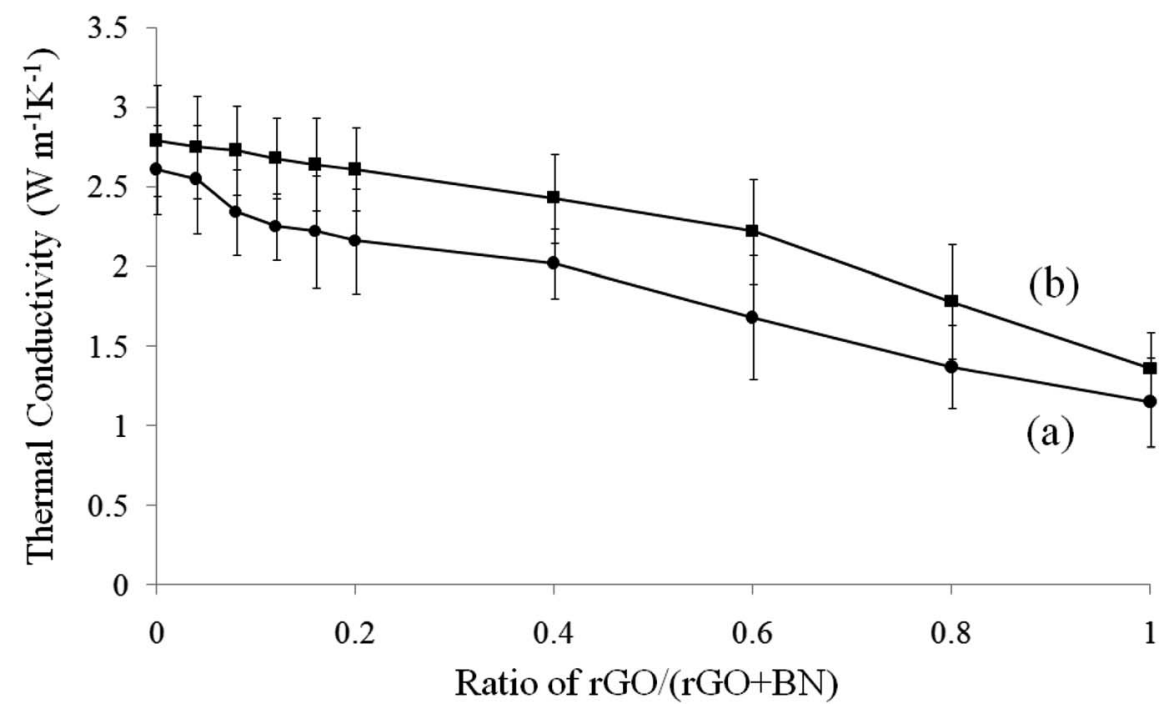

Fig. 10 Thermal conductivity of (a) rGO/BN/PEO and (b) $\mathrm{Ca}^{2+}$-coordinated rGO/BN/PEO nanocomposites. The ratio of rGO/(rGO + BN) changes from 0 to 1 . The ratio of ( $\mathrm{rGO}+\mathrm{BN}):$ PEO is constantly $10: 4$. 
conductivities of all samples increase by $10-30 \%$. This result indicates that due to the strong interfacial interaction provided by metal-ion coordination, BN and rGO can easily form thermal conductive networks.

From the results shown in the previous sections, a multifunctional nanocomposite (for example, $\mathrm{Ca}^{2+}$-coordinated $\mathrm{rGO} / \mathrm{BN} / \mathrm{PEO}$ with $\mathrm{rGO}: \mathrm{BN}: \mathrm{PEO}=4: 6: 4)$ with excellent mechanical (Young's modulus $=1.34 \mathrm{GPa}$, tensile strength $=52$ $\mathrm{MPa}$ ), electrical (electrical conductivity $=0.02 \mathrm{~S} \mathrm{~cm}^{-1}$ ) and thermal (thermal conductivity $=3.2 \mathrm{~W} \mathrm{~m}^{-1} \mathrm{~K}^{-1}$ ) performances can be prepared through our method. By changing the ratio of rGO : BN, the three properties can be adjusted. Thus, this metal-ion coordination method is a potential route for fabricating multi-functional nanocomposites with desirable properties.

\section{Conclusions}

Here, we demonstrate a simple and cost-effective strategy for preparing multi-functional nanocomposites through strong interfacial interactions of coordination bonds by divalent metal ions. The strong interaction provides efficient load transfer to significantly improve the mechanical property, and it is easier for nanomaterials to form conductive networks to improve electrical and thermal properties. The product shows excellent performance in all three aspects: mechanical, electrical and thermal. This strategy is applicable to a variety of nanomaterials and polymers containing coordination atoms with different properties, opening up a new opportunity for fabricating multifunctional nanocomposites.

\section{Conflicts of interest}

There are no conflicts to declare.

\section{Acknowledgements}

We thank the National Natural Science Foundation of China (No. 51633003) and the STI program of Shenzhen (No. JCYJ20160428182212366) for financial support.

\section{References}

1 C. Lee, X. D. Wei, J. W. Kysar and J. Hone, Measurement of the elastic properties and intrinsic strength of monolayer graphene, Science, 2008, 321, 385-388.

2 X. Du, I. Skachko, A. Barker and E. Y. Andrei, Approaching ballistic transport in suspended graphene, Nat. Nanotechnol., 2008, 3, 491-495.

3 S. Stankovich, D. A. Dikin, G. H. B. Dommett, K. M. Kohlhaas, E. J. Zimney, E. A. Stach, R. D. Piner, S. T. Nguyen and R. S. Ruoff, Graphene-based composite materials, Nature, 2006, 442, 282-286.

4 R. K. Layek, S. Samanta, D. P. Chatterjee and A. K. Nandi, Physical and mechanical properties of poly(methyl methacrylate) -functionalized graphene/poly(vinylidine fluoride) nanocomposites: Piezoelectric b polymorph formation, Polymer, 2010, 51, 5846-5856.

5 Z. Q. Duan, Y. T. Liu, X. M. Xie and X. Y. Ye, A simple and green route to transparent boron nitride/PVA nanocomposites with significantly improved mechanical and thermal properties, Chin. Chem. Lett., 2013, 24, 17-19.

6 Y. T. Liu, X. M. Xie and X. Y. Ye, Tuning the solubility of boron nitride nanosheets in organic solvents by using block copolymer as a "Janus" modifier, Chem. Commun., 2013, 49, 388-390.

7 D. Zheng, G. S. Tang, H. B. Zhang, Z. Z. Yu, F. Yavari, N. Koratkar, S. H. Lim and M. W. Lee, In situ thermal reduction of graphene oxide for high electrical conductivity and low percolation threshold in polyamide 6 nanocomposites, Compos. Sci. Technol., 2012, 72, 284-289.

8 D. S. Yu, T. Kuila, N. H. Kim and J. H. Lee, Enhanced properties of aryl diazonium salt-functionalized graphene/ poly(vinyl alcohol) composites, Chem. Eng. J., 2014, 245, 311-322.

9 Y. Wang, C. Shen, W. Lou and F. Shentu, Fiber optic humidity sensor based on the graphene oxide/PVA composite film, Opt. Commun., 2016, 372, 229-234.

10 W. L. Song, P. Wang, L. Cao, A. Anderson, M. J. Meziani, A. J. Farr and Y. P. Sun, Polymer/boron nitride nanocomposite materials for superior thermal transport performance, Angew. Chem., Int. Ed., 2012, 51, 6498-6501.

11 Y. Wang, Z. Shi and J. Yin, Boron nitride nanosheets: largescale exfoliation in methanesulfonic acid and their composites with polybenzimidazole, J. Mater. Chem., 2011, 21, 11371-11377.

12 A. Abbas, Y. Zhao, J. G. Zhou, X. Wang and T. Lin, Improving Thermal Conductivity of Cotton Fabrics Using Composite Coatings Containing Graphene, Multiwall Carbon Nanotube or Boron Nitride Fine Particles, Fibers Polym., 2013, 14, 1641-1649.

13 Y. M. Yao, X. L. Zeng, F. F. Wang, R. Sun, J. B. Xu and C. P. Wong, Significant Enhancement of Thermal Conductivity in Bioinspired Freestanding Boron Nitride Papers Filled with Graphene Oxide, Chem. Mater., 2016, 28, 1049-1057.

14 H. Liem and H. S. Choy, Superior thermal conductivity of polymer nanocomposites by using graphene and boron nitride as fillers, Solid State Commun., 2013, 163, 41-45.

15 X. K. Chen, Z. X. Xie, W. X. Zhou and K. Q. Chen, The thermal conductivity in hybridizedgraphene and boron nitride nanoribbons modulated with strain, J. Phys. D: Appl. Phys., 2016, 49, 115301.

16 C. Lin, Y. T. Liu and X. M. Xie, Improved Mechanical Properties of Graphene oxide/Poly (ethylene oxide) nanocomposites by dynamic interfacial interaction of coordination, Aust. J. Chem., 2014, 67, 121-126.

17 L. Pan, Y. T. Liu, X. M. Xie and X. D. Zhu, CoordinationDriven Hierarchical Assembly of Silver Nanoparticles on $\mathrm{MoS}_{2}$ Nanosheets for Improved Lithium Storage, Chem.Asian J., 2014, 9, 1519-1524.

18 Y.-T. Liu, Z. Tan, X. M. Xie, Z. F. Wang and X. Y. Ye, Processable and Robust $\mathrm{MoS}_{2}$ Paper Chemically Cross- 
Linked with Polymeric Ligands by the Coordination of Divalent Metal Ions, Chem.-Asian J., 2013, 8, 817-823.

19 M. zhong, Y. T. Liu and X. M. Xie, Self-healable, super tough graphene oxide-poly(acrylic acid) nanocomposite hydrogels facilitated by dual cross-linking effects through dynamic ionic interactions, J. Mater. Chem. B, 2015, 3, 4001-4008.

20 N. Chen and X. M. Xie, Confined crystallization of poly(ethylene oxide) under copper(II) ion coordinationdefect-induced melting point depression, Acta Polym. Sin., 2013, 5, 635-642.

21 Y. T. Liu, Q. P. Feng, X. M. Xie and X. Y. Ye, The production of flexible and transparent conductive films of carbon nanotube/graphene networks coordinated by divalent metal (Cu, Ca or Mg) ions, Carbon, 2011, 49, 3371-3375.

22 W. S. Hummers and R. E. Offeman, Preparation of graphitic oxide, J. Am. Chem. Soc., 1958, 80, 1339.

23 Y. T. Liu, M. Dang, X. M. Xie, Z. F. Wang and X. Y. Ye, Synergistic effect of $\mathrm{Cu}^{2+}$-coordinated carbon nanotube/ graphene network on the electrical and mechanical properties of polymer nanocomposites, J. Mater. Chem., 2011, 21, 18723-18729.

24 D. R. Dreyer, S. Park, C. W. Bielawski and R. S. Ruoff, The chemistry of graphene oxide, Chem. Soc. Rev., 2010, 39, 228-240.

25 Y. Lin, T. V. Williams, T. B. Xu, W. Cao, H. E. Elsayed-Ali and J. W. Connell, Aqueous dispersions of few-layered and monolayered hexagonal boron nitride nanosheets from sonication-assisted hydrolysis: critical role of water, J. Phys. Chem. C, 2011, 115, 2679-2685.
26 J. I. Paredes, S. Villar-Rodil, A. Martínez-Alonso and J. M. Tascon, Graphene oxide dispersions in organic solvents, Langmuir, 2008, 24, 10560-10564.

27 D. C. Marcano, D. V. Kosynkin, J. M. Berlin, A. Sinitskii, Z. Sun, A. Slesarev, L. B. Alemany, W. Lu and J. M. Tour, Improved synthesis of graphene oxide, ACS Nano, 2010, 4, 4806-4814.

28 Y. Wang, Z. Shi and J. Yin, Boron nitride nanosheets: largescale exfoliation in methanesulfonic acid and their composites with polybenzimidazole, J. Mater. Chem., 2011, 21, 11371-11377.

29 Q. Luo, Y. Shan, X. Zuo and J. Liu, Anisotropic tough poly(vinyl alcohol)/grapheneoxide nanocomposite hydrogels for potentialbiomedical applications, RSC Adv., 2018, 8, 13284-13291.

30 S. Stankovich, D. A. Dikin, R. D. Piner, K. A. Kohlhaas, A. K. Kleinhammes, Y. Jia, Y. Wu, S. T. Nguye and R. S. Ruoff, Synthesis of graphene-based nanosheets via chemical reduction of exfoliated graphite oxide, Carbon, 2007, 45, 1558-1565.

31 P. G. Ren, D. X. Yan, X. Ji, T. Chen and Z. M. Li, Temperature dependence of graphene oxide reduced by hydrazine hydrate, Nanotechnology, 2011, 22, 055705.

32 Y. T. Liu, J. M. Yang, X. M. Xie and X. Y. Ye, Polystyrenegrafted graphene with improved solubility in organic solvents and its compatibility with polymers, Mater. Chem. Phys., 2011, 130, 794-799. 